\title{
Potato and high-amylose maize starches are not equivalent producers of butyrate for the colonic mucosa
}

\author{
Lucile J. M. Martin ${ }^{1,2,3}$, Henri J. W. Dumon ${ }^{1,3}$, Gérard Lecannu ${ }^{2,3}$ and Martine M. J. Champ ${ }^{2,3 *}$ \\ ${ }^{1}$ Ecole Nationale Vétérinaire, Laboratoire de Nutrition et Alimentation, CP 3013, 44087 Nantes Cedex 03, France \\ ${ }^{2}$ Institut National de la Recherche Agronomique, Laboratoire Fonctions Digestives et Nutrition Humaine BP 71627, 44316 \\ Nantes Cedex 03, France \\ ${ }^{3}$ CRNH groupe métabolisme, Hôtel Dieu, Place A. Ricordeau, 44093 Nantes Cedex 01, France
}

(Received 18 March 1999 - Revised 22 February 2000 - Accepted 18 April 2000)

\begin{abstract}
Portal appearance of short-chain fatty acids (SCFA) produced from fermentation of three different resistant starch (RS) sources (raw potato starch, high-amylose maize starch and retrograded high-amylose maize starch) was investigated in pigs. The catheterization technique coupled with determination of portal blood flow was used to estimate SCFA uptake by the colonic mucosa. Our hypothesis was that these three RS were not equivalent butyrate providers for the colonic mucosa and that butyrate uptake would therefore be different after in vivo fermentation of each starch. The starches induced different patterns of appearance of SCFA in the portal blood; raw potato starch was the only RS source to show a significant appearance of butyrate in the portal blood. Thus, uptake of butyrate by the colonic mucosa apparently differed between starches. This finding suggests that butyrate uptake does not only depend on the flow of butyrate appearing in the lumen. Indeed, for unexplained reasons, utilization of butyrate by the colonic mucosa appeared to be less efficient when the butyrate was produced from fermentation of potato starch than when it was produced from fermentation of the other RS sources.
\end{abstract}

Resistant starch: Butyrate: Pig: Portal appearance: Colonic mucosa uptake

Resistant starches (RS) are defined as: 'the sum of starch and products of starch degradation not absorbed in the small intestine of healthy subjects' (Asp, 1992). They undergo bacterial fermentation in the colon (Cummings \& Englyst, 1987) producing short-chain fatty acids (SCFA), particularly butyrate in the hindgut (Annison \& Topping, 1994). Butyrate is the major fuel of colonocytes (DarcyVrillon et al. 1996), and its positive effect on the treatment or prevention of colonic cancer is now widely recognised (Hague et al. 1997). RS are therefore claimed to be beneficial in reducing the risk of colon cancer (Bingham, 1990). However, it remains uncertain as to whether RS inhibits colonic carcinogenesis. Results from previous studies indicate that some starches are protective against tumour development (Thorup et al. 1995; Caderni et al. 1996; Kristiansen et al. 1996; Perrin et al. 2000) whereas other starches fail to protect and may enhance tumourigenesis (Calvert et al. 1989; Sakamoto et al. 1996; Young et al. 1996). There are numerous sources of RS which differ widely in their characteristics (e.g. different structure of starch granules and different food processing procedures). Uncooked potato starch may exhibit some deleterious effects on the colonic mucosa, but the exact mechanism remains unknown (Young et al. 1996).

Thus we can consider whether these different sources of RS are equivalent butyrate providers for the colonocytes, and whether the kind of RS could have an impact on butyrate uptake by the colonic mucosa. However, these questions are difficult to solve in human subjects as invasive investigations would need to be performed. We therefore used the pig as an animal model for man. The pig is an omnivore with a gut physiology close to that of man (Topping et al. 1985). Moreover, Bach Knudsen (1991) determined that digestive transit time is similar for pigs and human subjects. We measured the rate of appearance in the portal vein of the butyrate produced from the fermentation of three different starches: raw potato starch (PoS), highamylose maize starch (HS) and retrograded high-amylose maize starch (RHS). We used the catheterization technique coupled with determination of portal blood flow to estimate

\footnotetext{
Abbreviations: HS, high-amylose maize starch; PoS, raw potato starch; RHS, retrograded high-amylose maize starch; RS, resistant starch; SCFA, short-chain fatty acids.

* Corresponding author: Dr Martine Champ, fax +33 24067 5012, email champ@nantes.inra.fr
} 
uptake by the colonic mucosa. We hypothesised that the flow of acetate appearing in the portal vein reflected the hindgut production of acetate from colonic fermentation of the starches. Indeed, only a small proportion of acetate is metabolised by the colonic mucosa (Roediger, 1995). We estimated the flow of butyrate metabolised by the colonic mucosa from the concentration of acetate appearing in the portal vein and the in vitro ratio of SCFA for the same starches previously determined using pig inocula by Martin et al. (1998).

\section{Experimental methods}

\section{Animals}

Four female pigs with an initial body weight of 35 (SD 1.5) $\mathrm{kg}$ were used. The pigs were fed on a body-weight basis $(1200 \mathrm{~kJ}$ metabolizable energy/kg metabolic weight $0 \cdot 75)$. Water was provided ad libitum. Throughout the study (adaptation and test periods) pigs were housed individually in metabolism cages in a room with a controlled temperature of $20^{\circ} \mathrm{C}$. Animals were fed a meal twice daily at 07.30 hours and 15.00 hours. The experimental diet was mixed with water immediately before feeding $(1: 2, \mathrm{w} /$ v). Animal welfare was always in accordance with French legislation.

\section{Diets}

Three RS sources, PoS (Roquette, Lestrem, France), HS (National Starch, Bridgewater, NJ, USA) or RHS (Cerestar, Vilvoorde, Belgium) were included in three different diets. The compositions of the experimental diets are shown in Table 1 . The metabolizable energy content $(\mathrm{kJ} / \mathrm{kg} \mathrm{DM})$ was 17 200, 17130 and 17150 for the PoS, HS and RHS diets respectively. The diets were formulated to provide $30 \mathrm{~g}$ indigestible carbohydrate/d during the adaptation period. The RS were the only source of indigestible material in the diets of the pigs. The amount of RS ingested on the day of the experiment was $0.9 \mathrm{mg} \mathrm{RS} / \mathrm{kJ}$ which corresponds with the estimated human consumption reported by Brighenti $e t$

Table 1. Composition of the experimental diets $(\mathrm{g} / \mathrm{kg})^{*}$

\begin{tabular}{lccc}
\hline Diet... & PoS & HS & RHS \\
\hline Pregelatinised potato starch & $544 \cdot 6$ & $514 \cdot 8$ & $440 \cdot 2$ \\
Meat meal & $124 \cdot 0$ & $124 \cdot 0$ & $124 \cdot 0$ \\
Skimmed-milk powder & $82 \cdot 0$ & $82 \cdot 0$ & $82 \cdot 0$ \\
Maize oil & $46 \cdot 0$ & $46 \cdot 0$ & $46 \cdot 0$ \\
Lard & $96 \cdot 0$ & $96 \cdot 0$ & $96 \cdot 0$ \\
Beet sugar & $54 \cdot 0$ & $54 \cdot 0$ & $54 \cdot 0$ \\
PoS & $53 \cdot 4$ & - & - \\
HS $^{\ddagger}$ & - & $83 \cdot 2$ & - \\
RHS $^{\S}$ & - & - & $157 \cdot 8$ \\
Metabolizable energy (kJ/kg DM) & 17200 & 17130 & 17150 \\
\hline
\end{tabular}

PoS, raw potato starch; HS, high-amylose maize starch; RHS, retrograded high-amylose maize starch.

${ }^{*}$ Vitamin and mineral mix (vitabiose ${ }^{\circledR}$; Schering-Plough, Segre, France) was included at $15 \mathrm{~g} / \mathrm{d}$ per animal.

$\dagger$ Roquette, Lestrem, France.

‡ National Starch, Bridgewater, USA.

$\S$ Cerestar, Vilvoorde, Belgium. al. (1998). Each pig received each of the three diets at random for $5 \mathrm{~d}$ (adaptation period) before sampling.

\section{Experimental procedure}

Each animal was anaesthetised by inhalation of a mixture of halothane (Belamont, Paris, France), nitrogen protoxide and $\mathrm{O}_{2}$ via a mask (with $4 \%(\mathrm{v} / \mathrm{v})$ halothane for induction and $2 \%(\mathrm{v} / \mathrm{v})$ for anaesthesia, and $\mathrm{O}_{2}$ and nitrogen protoxide each at $1.5 \mathrm{l} / \mathrm{min}$ ). Pigs were fitted with a $14 \mathrm{~mm}$ Transonic ${ }^{\circledR}$ blood-flow probe (Transonic Systems Ltd, Ithaca, NY, USA) around the portal vein. Indwelling catheters were used in the portal vein, left jugular vein and left carotid artery. The catheter site in the portal vein was chosen to prevent interference with the measurement of blood flow. The portal-vein catheter and the probe flex were exteriorized through the body wall on the right flank, and the jugular and carotid catheters were exteriorized between the shoulder blades. The catheters were flushed daily with a solution of heparinized $(50 \mathrm{IU} / \mathrm{ml})$ physiological saline $(9 \mathrm{~g} \mathrm{NaCl} / \mathrm{l})$ solution. The jugular catheter was only used to perfuse lactate Ringer solution to the animals for the post-operative recovery $(24 \mathrm{~h})$. It was not used for blood collection.

Animals were adapted to each diet for $5 \mathrm{~d}$ and then fasted for $16 \mathrm{~h}$ on day 6 . On day 7 at 07.30 hours each pig was fed its morning meal, containing $15 \mathrm{~g}$ RS. A painless blood sample ( $5 \mathrm{ml}$ blood per vessel) was taken from the conscious animal before mealtime $(-15 \mathrm{~min})$ and hourly for the next $14 \mathrm{~h}$. Samples were immediately centrifuged $\left(3500 \mathrm{~g} ; 4^{\circ} \mathrm{C}\right)$. Portal blood flow $(\mathrm{ml} / \mathrm{kg}$ per $\mathrm{min})$ was recorded continuously during the experimental trial. Plasma samples were kept at $-80^{\circ} \mathrm{C}$ before analysis. The SCFA analyses were performed using the procedure described by Brighenti (1997).

\section{Calculations and statistics}

The ultrasonic blood-flow probe was directly linked to a computer (Acer 760C, Amsterdam, The Netherlands) which recorded instantaneous data and produced a value for the integrated flow rate.

The plasma samples obtained from the hepatic portal vein and carotid artery were analysed for acetate, propionate, and butyrate. The appearance of SCFA in the portal circulation was calculated according to the formula of Rérat et al. (1980). This method is based on the quantitative determination of the increase in nutrients within intestinal blood flow after a meal according to the formula:

$$
\int_{t_{0}}^{t_{1}} d Q=\int_{t_{0}}^{t_{1}}\left(c_{p}(t)-c_{a}(t)\right) \times D(t) \times d t,
$$

where $\int d Q$ (mmol) is the quantity absorbed during the experimental period, $c_{p}(\mu \mathrm{mol} / \mathrm{l})$ is the concentration of nutrients in the hepatic portal vein, $c_{a}(\mu \mathrm{mol} / \mathrm{l})$ is the concentration in arterial blood and $D(t)(1 / \mathrm{min})$ is the portal-blood flow rate during the short period of time $d t$.

The colonic uptake of butyrate was estimated hourly 
using the following formula:

$$
\mathrm{y}=\int \mathrm{dq} \times\left(\% \mathrm{C}_{4} \text { in vitro }\right) /\left(\% \mathrm{C}_{2} \text { in vitro }\right),
$$

where $\int \mathrm{dq}(\mathrm{mmol} / \mathrm{h})$ is the quantity of acetate absorbed in $1 \mathrm{~h}, \% \mathrm{C}_{4}$ in vitro is the butyrate- $\sum \mathrm{SCFA}$ measured in vitro and $\% \mathrm{C}_{2}$ in vitro is the acetate- $\sum \mathrm{SCFA}$ measured in vitro.

In order to take into account the possible effect of the adaptation of the colonic flora, the 'pre-treatment' factor was added to the statistical analysis (Van der Meulen et al. 1997). Data were analysed by ANOVA with diet, animal and pre-treatment as main factors. No pre-treatment effect was apparent for any variables. When the effect of the diet was significant (F test, $P<0 \cdot 05$ ), the differences in mean values between diets were assessed by the Fisher's least significant difference test (matrix of pairwise comparison probabilities). The total amounts of SCFA and butyrate (diet PoS $v$. diets HS and RHS) that appeared in the portal vein were assessed by contrast analysis. $P<0.05$ was considered to be significant. The differences between the regression coefficients, calculated to estimate butyrate colonocyte uptake, were assessed by the ANCOVA analysis. All statistics were performed using SuperANOVA $^{\mathrm{TM}}$ Software (version 1.1, 1989; Abacus Concepts Inc., Berkeley, CA, USA).

\section{Results}

All pigs ate the three diets rapidly and remained in good health throughout the $21 \mathrm{~d}$ experiment. The mean quantities of starch consumed on the experimental days were $27.5,41.0$ and $82.6 \mathrm{~g} / \mathrm{d}$, corresponding to 15.4 (SEM 1.8), 14.8 (SEM 1.1) and 15.7 (SEM 1.1) g RS/d for the PoS, HS and RHS diets respectively. The values were not significantly different between trials.

\section{Portal-blood flow rate}

Throughout the $14 \mathrm{~h}$ trial, the average portal-blood flow rate was slightly higher $(P=0 \cdot 01)$ after the RHS meal than after the other meals (Table 2). Regardless of the RS used, an increase in the portal-blood flow rate was detectable immediately after the morning meal. The values began to decrease 3-4 h after the meal, with the lowest flow rate occurring at the end of the measurement (between 11 and $14 \mathrm{~h}$ after the meal).

\section{Arterial and portal short-chain fatty acid concentrations}

Only acetate was found in peripheral blood (carotid artery), regardless of the diet used (Table 2). Mean arterial concentrations (fifteen values per pig and per diet for four pigs) were significantly higher with the RHS diet than with the HS and PoS diets $(P<0.001)$.

The mean portal concentrations were higher than the corresponding arterial concentrations, and all three SCFA appeared in the portal blood, regardless of the starch used in the diet (Table 2). The highest mean SCFA concentration in portal blood was measured with RHS $(P<0.001)$. The mean concentration of acetate was also significantly $(P<$ 0.001) higher after consumption of diet RHS than after consumption of the other diets. However, significantly higher concentrations of propionate $(P=0.001)$ and butyrate $(P<0.001)$ were measured in the portal vein after consumption of PoS starch. As described by several authors (Giusi-Périer et al. 1989; Rérat, 1996) for other sources of fermentable carbohydrates, SCFA concentrations decreased during the first $3 \mathrm{~h}$ and then increased during the remaining $11 \mathrm{~h}$ of the experimental period after PoS or HS ingestion. For RHS, small variations were observed during the whole postprandial period.

\section{Amounts of short-chain fatty acids in portal blood}

The quantities of SCFA appearing in the portal vein after ingestion of the PoS and HS meals decreased during the first $4 \mathrm{~h}$ of the experimental period and then increased. However, after ingestion of RHS, a high rate of SCFA absorption in the portal blood was observed in the early phase of the measurement, with relatively small variations in SCFA concentration thereafter. Thus, to avoid any carryover fermentation effects from RS in previous meals, data

Table 2. Portal blood-flow rate and short-chain fatty acid (SCFA) concentrations in pigs during a $14 \mathrm{~h}$ period following consumption of a meal containing raw potato starch (PoS), high-amylose maize starch (HS) or retrograded high-amylose maize starch (RHS) $\dagger$ (Mean values with their standard errors for four pigs)

\begin{tabular}{|c|c|c|c|c|c|c|c|}
\hline \multirow[b]{2}{*}{ Dietary starch... } & \multicolumn{2}{|c|}{ PoS } & \multicolumn{2}{|c|}{ HS } & \multicolumn{2}{|c|}{ RHS } & \multirow{2}{*}{$\begin{array}{c}\text { Statistical significance of } \\
\text { difference between treatments: } P\end{array}$} \\
\hline & Mean & SE & Mean & SE & Mean & SE & \\
\hline $\begin{array}{l}\text { Portal blood-flow rate }(\mathrm{ml} / \mathrm{kg} \text { per } \mathrm{min}) \\
\text { Arterial concentration }(\mu \mathrm{mol} / \mathrm{l})\end{array}$ & $24 \cdot 3$ & 0.6 & 24.5 & 0.6 & $25 \cdot 0^{\star \star}$ & 0.7 & \\
\hline $\begin{array}{l}\text { Acetate } \\
\text { Propionate } \\
\text { Butyrate }\end{array}$ & $\begin{array}{l}121 \cdot 1^{\mathrm{a}} \\
\text { nd } \\
\text { nd }\end{array}$ & $3 \cdot 4$ & $\begin{array}{l}134 \cdot 3^{b} \\
\text { nd } \\
\text { nd }\end{array}$ & 3.7 & $\begin{array}{c}149 \cdot 4^{c} \\
\text { nd } \\
\text { nd }\end{array}$ & 9.5 & $<0.001$ \\
\hline Portal concentration $(\mu \mathrm{mol} / \mathrm{l})$ & & & & & & & \\
\hline $\begin{array}{l}\text { Acetate } \\
\text { Propionate } \\
\text { Butyrate } \\
\text { Total SCFA }\end{array}$ & $\begin{array}{r}236 \cdot 5^{\mathrm{a}} \\
47 \cdot 4^{\mathrm{a}} \\
21 \cdot 5^{\mathrm{a}} \\
305 \cdot 4^{\mathrm{a}}\end{array}$ & $\begin{array}{r}9 \cdot 6 \\
2 \cdot 3 \\
1 \cdot 5 \\
12 \cdot 5\end{array}$ & $\begin{array}{r}206 \cdot 4^{\mathrm{a}} \\
34 \cdot 1^{\mathrm{b}} \\
1 \cdot 5^{\mathrm{b}} \\
242 \cdot 0^{\mathrm{b}}\end{array}$ & $\begin{array}{r}10 \cdot 2 \\
2 \cdot 5 \\
1 \cdot 6 \\
13 \cdot 3\end{array}$ & $\begin{array}{r}321 \cdot 5^{\mathrm{b}} \\
38 \cdot 8^{\mathrm{b}} \\
2 \cdot 6^{\mathrm{b}} \\
363 \cdot 0^{\mathrm{c}}\end{array}$ & $\begin{array}{r}11 \cdot 1 \\
2.7 \\
1 \cdot 7 \\
14 \cdot 5\end{array}$ & $\begin{array}{r}<0.001 \\
0.001 \\
<0.001 \\
<0.001\end{array}$ \\
\hline
\end{tabular}

nd, not detected.

$\mathrm{a}, \mathrm{b}, \mathrm{c}$ Mean values within a row with unlike superscript letters were significantly different at the levels indicated.

Mean values were significantly higher than that for PoS and HS: ${ }^{\star \star} P=0.01$

† For details of diets and procedures, see Table 1 and p. 690 


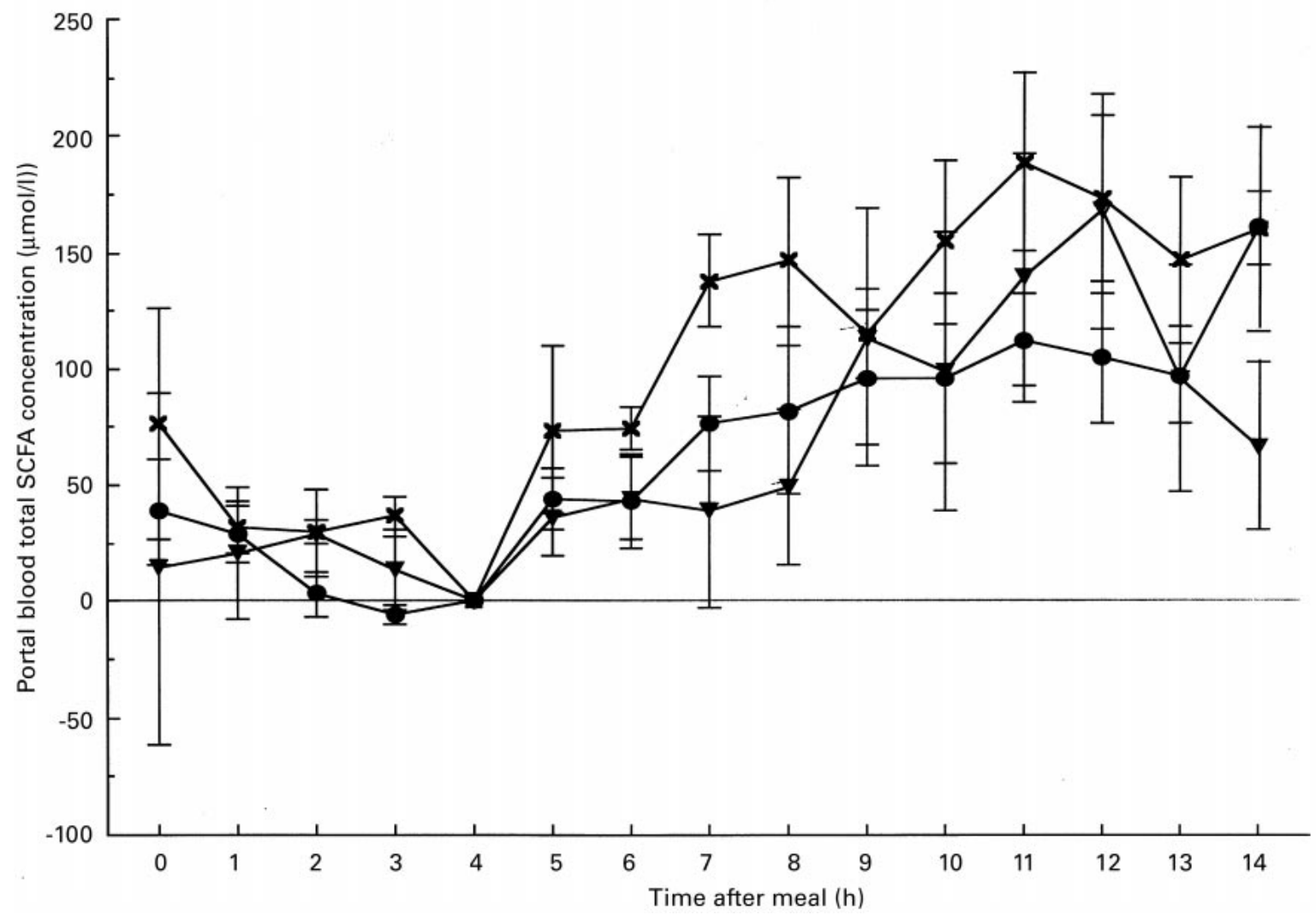

Fig. 1. Appearance of total short-chain fatty acids (SCFA) in the portal blood of pigs during a $14 \mathrm{~h}$ test period following consumption of a morning meal containing raw potato starch $(\times)$, high-amylose maize starch $(\bullet)$ or retrograded high-amylose maize starch $(\boldsymbol{\nabla})$. Data are presented with SCFA concentrations at $4 \mathrm{~h}$ as the base value to avoid any carry-over fermentation effects from resistant starch in previous meals. Values were calculated according to the following formula: $(\mathrm{Cp}-\mathrm{Ca})-\left(\mathrm{Cp}_{4 \mathrm{~h}}-\mathrm{Ca}_{4 \mathrm{~h}}\right)$, where $\mathrm{Cp}$ and $\mathrm{Ca}$ are the total SCFA concentrations in the portal blood and carotid artery respectively, and $\mathrm{Cp}_{4 \mathrm{~h}}$ and $\mathrm{Ca}_{4 \mathrm{~h}}$ are the SCFA concentrations in the portal blood and carotid artery at $4 \mathrm{~h}$ respectively. Values are raw means with their standard errors represented by vertical bars for four pigs. For details of diets and procedures, see Table 1 and $p$. 690 .

were recalculated with concentrations of SCFA at $4 \mathrm{~h}$ as the basal value (Figs. 1 and 2). According to this calculation, the total amount of SCFA measured postprandially in the portal vein during $14 \mathrm{~h}$ was significantly higher $(P=0.04)$ with the PoS $(75.7 \mathrm{mmol})$ than with the HS (42.8 mmol) and RHS (44.4 mmol) diets.

The comparison between the quantities of SCFA appearing in portal blood during three different periods of postprandial absorption $(0-4 \mathrm{~h}, 4-8 \mathrm{~h}$ and $8-14 \mathrm{~h}$ (Table 3)) showed differences with the time elapsed for PoS $(P=0.020)$ and HS $(P=0.023)$. The highest appearance of SCFA in the portal blood for PoS and HS starches was observed at 8-14 h. For RHS, SCFA appearing in the portal vein showed the lowest variations $(P>0 \cdot 05)$, although they increased slightly throughout the experimental period.

The most noteworthy result concerned the amount of butyrate appearing in the portal vein (Fig. 2). PoS induced a much greater $(P<0.001)$ appearance of butyrate $(11.9 \mathrm{mmol})$ than either RHS $(3.8 \mathrm{mmol})$ or HS $(0.0 \mathrm{mmol})$. After consumption of PoS and RHS, the amounts of butyrate appearing in the portal vein decreased during the first $4 \mathrm{~h}$ of the experimental period and then increased (Fig. 2). The appearance of butyrate increased progressively from 5 to $14 \mathrm{~h}$ after PoS ingestion but after
RHS ingestion butyrate reached a plateau between 10 and $12 \mathrm{~h}$ and then decreased. With HS, very little butyrate was detectable in the portal vein.

We estimated the theoretical flow of butyrate produced from starch fermentation (Table 3) using the in vitro data of Martin et al. (1998). A regression analysis was carried out between the theoretical flow of butyrate and the estimated uptake by the colonic mucosa (theoretical flow - flow in the portal blood) (Fig. 3). For the PoS, the following equation was calculated: $\mathrm{y}=-0.436+0.678 \mathrm{x}\left(r^{2} 0.515\right.$; $P=0.0086)$, and for the two maize starches: $\mathrm{y}=0.022+$ $0.926 \mathrm{x}\left(r^{2} 0.979 ; P<0.001\right)$. The ANCOVA analysis revealed that the uptake of butyrate by the colonic mucosa differed between starches $(P=0.0001)$, although the slopes of the equations did not differ significantly $(P=$ $0 \cdot 1106)$.

\section{Discussion}

Many studies have investigated the role of RS in colonic functions, especially tumuorigenesis. RS, by stimulating digestive fermentation, especially butyrate production, is considered to provide protection against colonic cancer (Hylla et al. 1998). Nevertheless, the exact amounts of SCFA produced in the digestive tract after ingestion of 


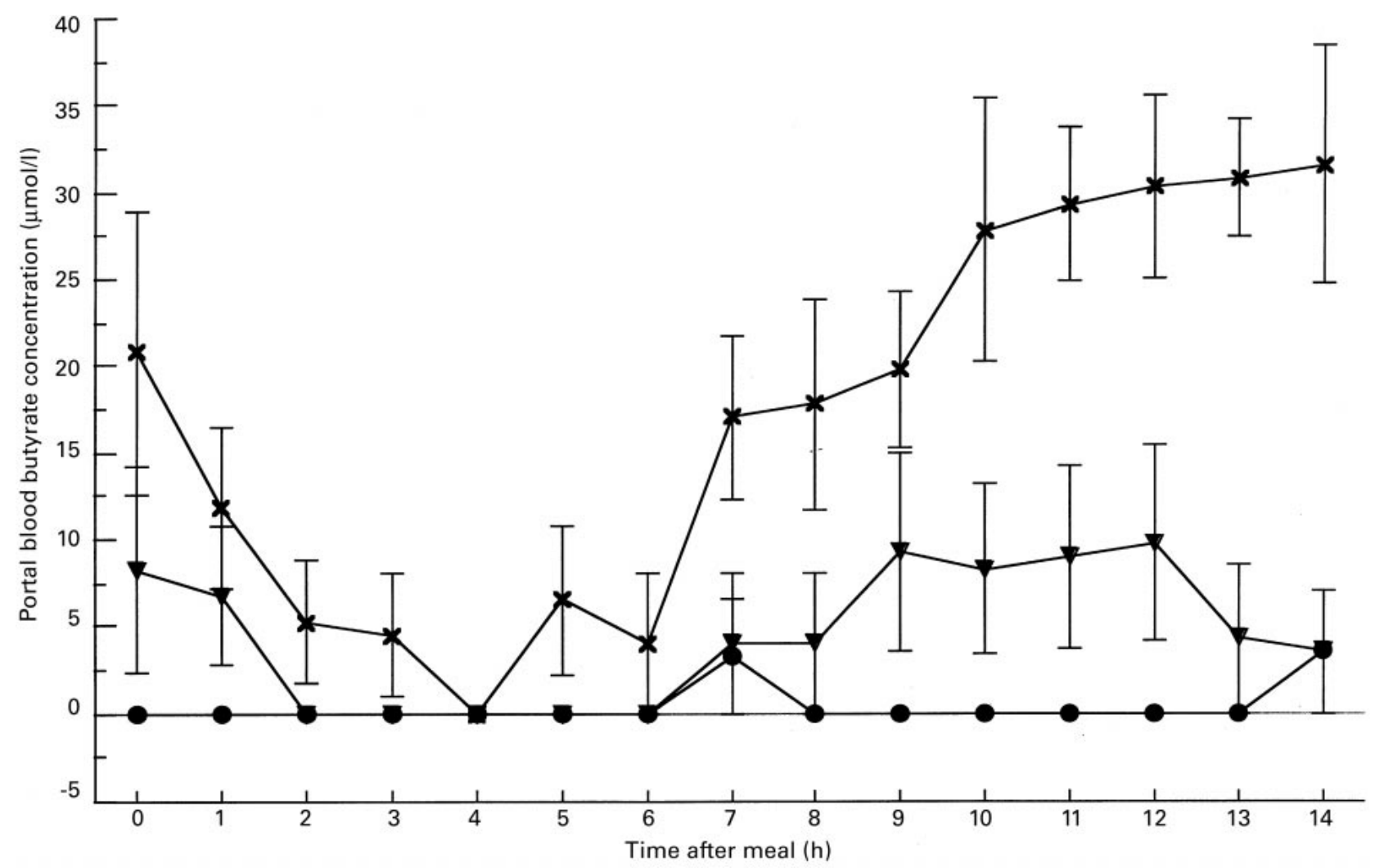

Fig. 2. Appearance of butyrate in the portal blood of pigs during a $14 \mathrm{~h}$ test period following consumption of a morning meal containing raw potato starch $(\times)$, high-amylose maize starch $(\bullet)$ or retrograded high-amylose maize starch $(\boldsymbol{\nabla})$. Data are presented with butyrate concentrations at $4 \mathrm{~h}$ as the base value to avoid any carry-over fermentation effects from resistant starch in previous meals. Values were calculated according to the following formula: $\left(\mathrm{Cp}-\mathrm{Cp}_{4 h}\right)$, where $\mathrm{Cp}$ is the butyrate concentration in the portal blood and $\mathrm{Cp}_{4 \mathrm{~h}}$ is the butyrate concentration in the portal blood at $4 \mathrm{~h}$. Values are raw means with their standard errors represented by vertical bars for four pigs. For details of diets and procedures, see Table 1 and p. 690.

Table 3. Amount of short-chain fatty acids (SCFA; mmol/h) appearing in the portal vein in $1 \mathrm{~h}$ after a morning meal and estimated theoretical flow of butyrate, in pigs during three different time periods following consumption of a morning meal containing raw potato starch (PoS), high-amylose maize starch (HS) or retrograded high-amylose maize starch $(\mathrm{RHS})^{*}$

(Mean values with their standard errors for four pigs)

\begin{tabular}{|c|c|c|c|c|c|c|c|}
\hline \multirow[b]{2}{*}{ Dietary starch... } & \multicolumn{2}{|c|}{ Pos } & \multicolumn{2}{|c|}{ HS } & \multicolumn{2}{|c|}{ RHS } & \multirow{2}{*}{$\begin{array}{c}\text { Statistical significance of } \\
\text { difference between treatments: } P\end{array}$} \\
\hline & Mean & SE & Mean & SE & Mean & SE & \\
\hline \multicolumn{8}{|l|}{ Acetate } \\
\hline T1 & $3 \cdot 72^{\mathrm{a}}$ & 0.588 & $2 \cdot 79^{a}$ & 0.677 & $8 \cdot 68^{b}$ & 1.49 & 0.005 \\
\hline T2 & $5 \cdot 97^{\mathrm{ab}}$ & 0.49 & $4 \cdot 25^{\mathrm{a}}$ & 0.21 & $8 \cdot 86^{b}$ & 1.56 & 0.022 \\
\hline T3 & $6 \cdot 89^{\mathrm{ab}}$ & 0.79 & $5 \cdot 58^{a}$ & 0.55 & $9 \cdot 77^{b}$ & 1.45 & 0.044 \\
\hline \multicolumn{8}{|l|}{ Butyrate } \\
\hline T1 & $0.78^{a}$ & 0.76 & $0.00^{a}$ & 0.00 & $0 \cdot 18^{a}$ & 0.11 & 0.091 \\
\hline T2 & $0.75^{\mathrm{a}}$ & 0.224 & $0.04^{\mathrm{b}}$ & 0.04 & $0.08^{b}$ & 0.08 & 0.009 \\
\hline T3 & $1.57^{\mathrm{a}}$ & 0.09 & $0.01^{a}$ & 0.01 & $0.36^{b}$ & 0.18 & 0.000 \\
\hline \multicolumn{8}{|l|}{ Total SCFA } \\
\hline T1 & $6 \cdot 60^{\mathrm{a}}$ & 0.96 & $4.04^{\mathrm{a}}$ & 1.07 & $10 \cdot 97^{b}$ & 1.64 & 0.011 \\
\hline T2 & $9 \cdot 24^{\mathrm{a}}$ & 0.88 & $5 \cdot 90^{\mathrm{b}}$ & 0.11 & $10 \cdot 99^{a}$ & 1.54 & 0.019 \\
\hline T3 & $11.38^{\mathrm{a}}$ & 1.04 & $7 \cdot 55^{\mathrm{b}}$ & 0.66 & $12 \cdot 55^{\mathrm{a}}$ & 1.50 & 0.028 \\
\hline \multicolumn{8}{|c|}{ Theoretical flow of butyrate produced from starch fermentation ${ }^{\dagger}$} \\
\hline T1 & $0.87^{\mathrm{a}}$ & 0.27 & $0.65^{\mathrm{a}}$ & 0.16 & $1 \cdot 80^{\mathrm{b}}$ & 0.31 & 0.010 \\
\hline T2 & $2 \cdot 18^{a}$ & 0.18 & $1 \cdot 12^{\mathrm{b}}$ & 0.05 & $2 \cdot 73^{\mathrm{a}}$ & 0.48 & 0.012 \\
\hline T3 & $2 \cdot 52^{\mathrm{a}}$ & 0.29 & $1.47^{\mathrm{b}}$ & 0.14 & $3 \cdot 00^{\mathrm{a}}$ & 0.45 & 0.021 \\
\hline
\end{tabular}

T1, 0-4 $\mathrm{h}$ after consumption of the morning meal; T2, 4-8 $\mathrm{h}$ after consumption of the morning meal; T3, 8-14 $\mathrm{h}$ after consumption of the morning meal.

a,b,c Mean, values within a row with unlike superscript letters were significantly different at the levels indicated.

* For details of diets and procedures, see Table 1 and p. 690.

† Calculated from the mean hourly amount of acetate appearing in the period vein in the present study and the in vitro SCFA ratio previously determined by Martin et al. (1998). 


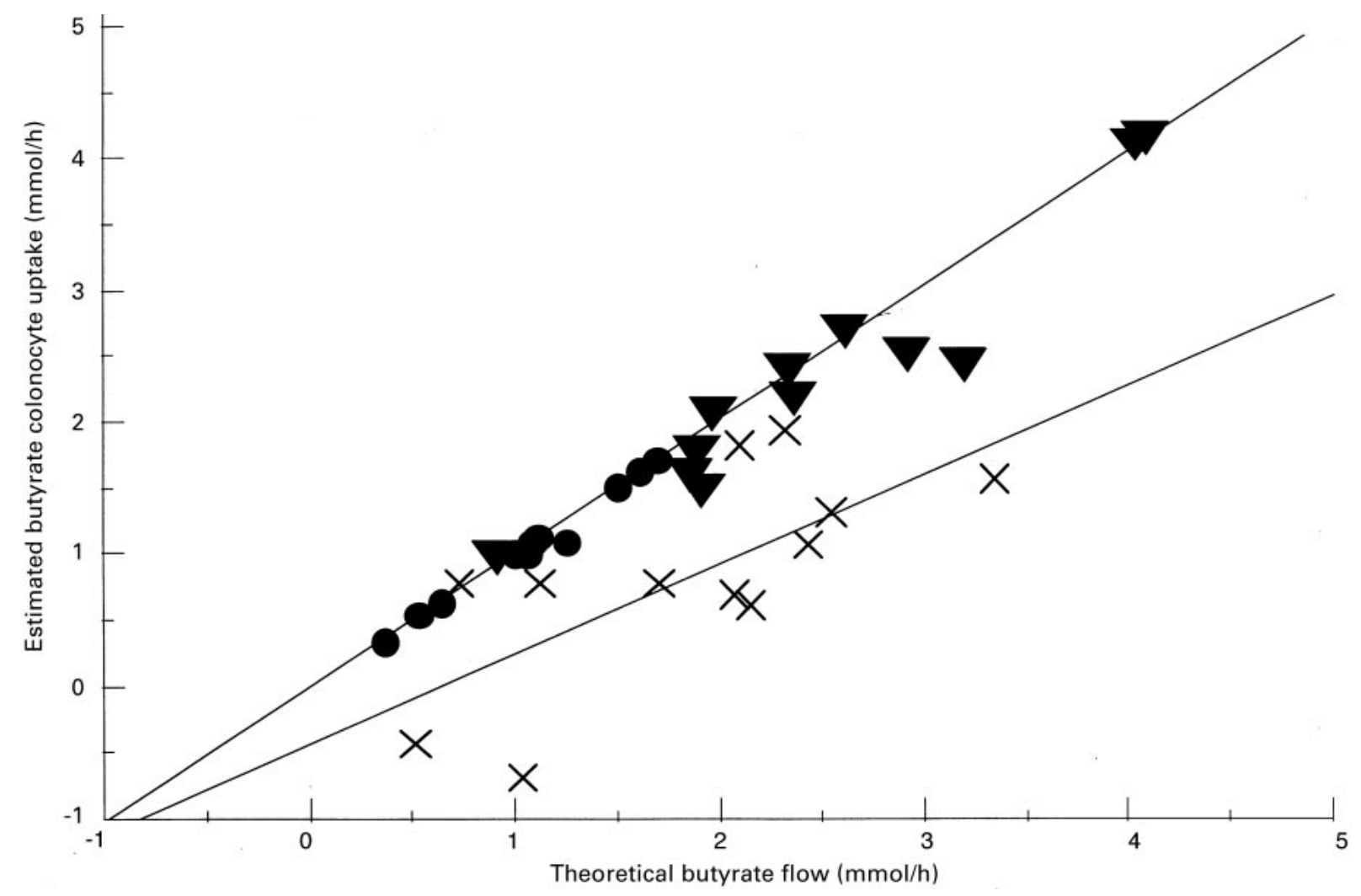

Fig. 3. Relationship between theoretical butyrate flow and estimated uptake of butyrate by the colonic mucosa in pigs following consumption of a morning meal containing raw potato starch $(\times)$, high-amylose maize starch $(\bullet)$ or retrograded high-amylose maize starch $(\boldsymbol{\nabla})$. The regression equations are: $\mathrm{y}=-0.436+0.678 \mathrm{x}\left(r^{2} 0.515 ; P=0.0086\right)$ for the raw potato starch; $\mathrm{y}=0.022+0.926 \times\left(r^{2} 0.979 ; P<0.001\right)$ for the two maize starches. The butyrate uptake by the colonic mucosa differed significantly between starches $(P=0.0001)$ but the slopes of the equations were not significantly different $(P=0 \cdot 1106)$.

various RS sources, and the proportion metabolised by colonocytes, remain unknown.

The present study was undertaken to investigate the absorption of the three main SCFA produced during caecocolonic fermentation of three RS sources, with a particular interest in butyrate. The method used to quantify absorption is based on simultaneous determination of the portal blood flow rate and measurement of porto-arterial differences in blood concentrations of SCFA (Noah et al. 2000).

In the present study, as well as in previous studies of nutrient absorption (Rérat et al. 1987, 1993; Ellis et al. 1995), there was no significant influence of meal composition on the mean blood flow rate. Like several authors (Rérat et al. 1987, 1993; Ellis et al. 1995), we noted that the blood flow increased just after a meal and during the first $4 \mathrm{~h}$ postprandially, then decreased dramatically.

The SCFA concentrations observed in arterial blood in the present study were in good agreement with values obtained in previous studies. Mean arterial concentrations measured in carotid blood were consistent with the values (90-190 $\mu \mathrm{mol} / \mathrm{l})$ reported by Rérat et al. (1987, 1993). In all cases, acetate was the only SCFA detected (Topping et al. 1985; Rérat et al. 1987; Yen et al. 1991). Indeed, propionate and butyrate appearing in portal blood are usually totally removed by the liver, whereas part of the acetate is released into peripheral blood (Demigné \& Rémésy, 1994).
The mean portal concentration of SCFA (all values pooled; $303 \mu \mathrm{mol} / \mathrm{l})$ was similar to values obtained by Giusi-Périer et al. (1989) with a diet containing only $6 \%$ of a poorly-fermented carbohydrate. Our diets also contained low amounts of fermentable material (15 g RS per meal) in order to simulate a human diet (Stephen, 1991; Southgate, 1998).

The rate of appearance of SCFA in the portal vein after a meal differed according to time period and type of starch. At the beginning of the blood collection SCFA appearance was between 4.0 and $11.0 \mathrm{mmol} / \mathrm{h}$. Two reasons could account for this observation. First, the duration of the fasting period $(16 \mathrm{~h})$ may not have allowed a complete fermentation of the indigestible fraction of the previous meals, as shown by Rérat et al. (1987). Second, some host products (such as mucin of the mucus layer and other endogenous proteins) are utilised by intestinal microflora (Conway, 1995) and their fermentation leads to SCFA production. In relation to the RHS diet, the amounts of SCFA were consistently higher than those with both the other diets, but no dramatic increase in SCFA was observed from $4 \mathrm{~h}$ after the experimental meal. This observation could be explained by the fact that the carry-over effect from the previous meal containing RHS was larger than that of the other diets. This possibility is consistent with our previous data (Martin et al. 1998), indicating that RHS contains a highly-resistant starch fraction which is not 
fermented after a $24 \mathrm{~h}$ in vitro fermentation with pig caecal microflora. It can be expected that, in vivo, this RS fraction was slowly fermented in the most distal part of the colon. This hypothesis is indeed confirmed by our earlier data (Martin et al. 1998); we measured a significantly higher amount of SCFA in the distal part of the colon with RHS starch $(5 \cdot 1$ (SEM 2.6) mmol) than with PoS (0.6 (SEM 0.5) mmol) and HS (2.0 (SEM 0.5) mmol) starches. PoS led to the highest absorption of SCFA, suggesting faster fermentation in the hindgut.

As far as butyrate is concerned, this SCFA is known to be the preferential fuel of colonocytes. Theoretically, the butyrate produced in the digestive lumen is totally absorbed and metabolised by colonocytes (Darcy-Vrillon et al. 1996). In our study, the highest amount of butyrate measured in the portal vein during the $14 \mathrm{~h}$ period following the experimental meal was observed with PoS. We estimated the theoretical uptake of butyrate by the colonic mucosa. It appeared that the calculated theoretical flow of butyrate produced from RS fermentation was similar for PoS and RHS. However, the colonic mucosa uptake was significantly greater for RHS than for PoS. The results of the present study indicate that the butyrate produced by RHS and HS from in vivo fermentation is almost entirely metabolised by the colonic mucosa. After PoS ingestion part of the butyrate produced by PoS fermentation appears in the portal vein. In the present study, the quantity of total SCFA carried across the colonic epithelium could be $1.5 \mu \mathrm{mol} / \mathrm{cm}^{2}$ per $\mathrm{h}$ if the area of the hindgut is estimated according to Argenizo (1982; $200 \mathrm{~cm}^{2} / \mathrm{kg}$ body weight). This value is lower than that previously obtained by Argenzio \& Southworth (1975; $3 \mu \mathrm{mol} / \mathrm{cm}^{2}$ per $\left.\mathrm{h}\right)$. These authors calculated a mucosal uptake of total SCFA of about $1.5 \mu \mathrm{mol} / \mathrm{cm}^{2}$ per $\mathrm{h}$, which is consistent with the butyrate uptake of $0.5 \mu \mathrm{mol} / \mathrm{cm}^{2}$ per $\mathrm{h}$ calculated according to our data.

Many studies have attempted to demonstrate the beneficial role of RS in the prevention of colonic cancers by stimulating digestive fermentation, especially butyrate production (Bingham, 1990). Nevertheless, Young et al. (1996) demonstrated that rats fed a diet containing $20 \%$ PoS had larger and more frequent tumours than rats consuming a basic diet or the same diet enriched with wheat bran. Other authors (Perrin, 1996; Sakamoto et al. 1996; Young et al. 1996) have also obtained contradictory results with different $\mathrm{RS}$ sources in relation to the potential beneficial effects of RS (and butyrate production) on aberrant crypt foci in rats exposed to carcinogens. Our results could partially explain those findings. Our data suggest different metabolism of the butyrate produced by different sources of RS; the butyrate produced by the fermentation of PoS may not be used efficiently by the colonocyte. Some authors suggested that different RS may well have different effects in the bowel lumen (Mallett et al. 1988; Mathers \& Dawson, 1991; Young et al. 1996). It has been suggested that the presence of $\mathrm{P}$ bonds could partially explain the effect of PoS in the digestive tract (Demigné \& Remésy, 1982). These authors suggested that the effect of PoS was associated with an increase in caecal blood flow and a more acidic caecal $\mathrm{pH}$. However, in our previous study (Martin et al. 1998) we did not observe a more acidic $\mathrm{pH}$ in the digestive contents of pigs fed the PoS diet.

\section{Conclusion}

The present study demonstrates that the consumption of diets containing various types of RS induces different patterns of appearance of SCFA in the portal blood. Among the three RS sources tested, only the PoS starch led to a significant appearance of butyrate in the portal blood. It seems that RS fermented in the most distal part of the colon (RHS in the present study) could be more beneficial for a healthy colon, since uptake of butyrate by the colonocytes is much higher. On the other hand, PoS could produce a large amount of butyrate without any benefit to the colonic epithelium. In order to prevent or to treat diseases of the colon, it would appear to be necessary to select RS sources not only with respect to their potential butyrate production, but also the in vivo metabolism of butyrate by the colonic mucosa.

\section{References}

Annison G \& Topping DL (1994) Nutritional role of resistant starch: chemical structure vs physiological function. Annual Review of Nutrition 14, 297-320.

Argenzio RA (1982) Volatile fatty acid production and absorption from the large intestine of the pig. In Physiologie Digestive chez le Porc (Digestive Physiology of the Pig). Les Colloques de l'INRA no. 12, pp. 207-215 [JP Laplace, T Corring and A Rérat, editors]. Paris: INRA.

Argenzio RA \& Southworth M (1975) Sites of organic acid production and absorption in the gastrointestinal tract of the pig. American Journal of Physiology 228, 454-460.

Asp NG (1992) Resistant starch. European Journal of Clinical Nutrition 46, Suppl. 2, 148.

Bach Knudsen KE (1991) Methodological aspects of in vivo methods for measuring starch digestibility: animal models. In Methodological Aspects of In Vivo Methods for the Measurement of Starch Digestibility. Report of a European Flair Concerted Action Workshop, pp. 40-57 [E Gudmand-Høyer, editor]. Copenhagen: Gentofle University Hospital.

Bingham SA (1990) Mechanisms and experimental and epidemiological evidence relating dietary fibre (non-starch polysaccharides) and starch to protection against large bowel cancer. Proceedings of the Nutrition Society 49, 153-171.

Brighenti F (1997) Simple method for quantitative analysis of short chain fatty acids in serum by gas-liquid chromatography. In Plant Polysaccharides in Human Nutrition: Structure, Function, Digestive Fate and Metabolic Effects, pp. 114-119 [F Guillon, H Andersson, NG Asp, KE Bach Knudsen, M Champ, J Robertson and J Van Loo, editors]. Nantes, France: INRA.

Brighenti F, Casiraghi MC \& Baggio C (1998) Resistant starch in the Italian diet. British Journal of Nutrition 80, 333-341.

Caderni G, Luceri C, Lancioni L \& Dolara P (1996) Dietary sucrose, glucose, fructose, and starches affect colonic functions in rats. Nutrition and Cancer 25, 179-186.

Calvert RJ, Otsuka M \& Satchithanandam S (1989) Consumption of raw potato starch alters intestinal function and colonic cell proliferation in the rat. Journal of Nutrition 119, 1610-1616.

Conway PL (1995) Microbial ecology of the human large intestine. In Human Colonic Bacteria: Role in Nutrition, 
Physiology and Pathology, pp. 1-24 [GR Gibson and GT Macfarlane, editors]. Boca Raton, FL: CRC Press.

Cummings JH \& Englyst HN (1987) Fermentation in the human large intestine and the available substrates. American Journal of Clinical Nutrition 45, 1243-1255.

Darcy-Vrillon B, Cherbuy C, Morel MT, Durand M \& Duée PH (1996) Short-chain fatty acid and glucose metabolism in isolated pig colonocytes: modulation by $\mathrm{NH}_{4}{ }^{+}$. Molecular and Cellular Biochemistry 156, 145-151.

Demigné C \& Rémésy C (1982) Influence of unrefined potato starch on cecal fermentations and volatile fatty acid absorption in rats. Journal of Nutrition 112, 2227-2234.

Demigné C \& Rémésy C (1994) Short chain fatty acid and hepatic metabolism. In Short Chain Fatty Acids. Falk Symposium no. 73, pp. 272-282 [HJ Binder, J Cummings and KH Soergel, editors]. Dordrecht, The Netherlands: Kluwer Academic Publishers.

Ellis PR, Roberts FG, Low AG \& Morgan LM (1995) The effect of high-molecular-weight guar gum on net apparent insulin and gastric inhibitory polypeptide production in the growing pig: relationship to rheological changes in jejunal digesta. British Journal of Nutrition 74, 539-556.

Giusi-Périer A, Fiszlewicz M \& Rérat A (1989) Influence of diet composition on intestinal volatile fatty acid and nutrient absorption in unanesthetized pigs. Journal of Animal Science 67, 386-402.

Hague A, Singh B \& Paraskeva C (1997) Butyrate acts as survival factor for colonic epithelial cells: further fuel for the in vivo versus in vitro debate. Gastroenterology 112, 1036-1040.

Hylla S, Gostner A, Dusel G, Bartram H-P, Christl SU, Kasper H \& Scheppach W (1998) Effects of resistant starch on the colon in healthy volunteers: possible implications for cancer prevention. American Journal of Clinical Nutrition 67, 136-142.

Kristiansen E, Meyer O \& Thorup I (1996) Refined carbohydrate enhancement of aberrant crypt foci (ACF) in rat colon induced by food-borne carcinogen 2-amino-3-methyl-imidazo[4,5-f]quinoline (IQ). Cancer Letters 105, 147-151.

Mallett AK, Bearne CA, Young PJ, Rowland IR \& Berry C (1988) Influence of starches of low digestibility on the rat caecal microflora. British Journal of Nutrition 60, 597-604.

Martin LMJ, Dumon HJW \& Champ MMJ (1998) Production of short chain fatty acids from resistant starch in a pig model. Journal of the Science of Food and Agriculture 77, 71-80.

Mathers JC \& Dawson LD (1991) Large bowel fermentation in rats eating processed potatoes. British Journal of Nutrition $\mathbf{6 6}$, 313-329.

Noah L, Krempf M, Lecannu G, Maugère P \& Champ M (2000) Bioavailability of starch and postprandial changes in splanchnic glucose metabolism in pigs. American Journal of Physiology 278, E181-E188.

Perrin P (1996) Modulation of cancer cells phenotype in rats by butyrate: application to immunotherapy and prevention for colon cancer. PhD Thesis, University of Nantes, France.

Perrin P, Pierre F, Patry Y, Champ M, Berreur M, Pradal G, Bornet F, Méflah K \& Ménanteau J (2000) Only fibers promoting a stable butyrate-producing colonic ecosystem decrease the rate of aberrant crypt foci in rats. Gut (In the Press).

Rérat AA (1996) Influence of the nature of carbohydrate intake on the absorption chronology of reducing sugars and volatile fatty acids in pigs. Reproduction Nutrition Développement 36, 3-19.

Rérat AA, Fislewicz M, Giusi A \& Vaugelade P (1987) Influence of meal frequency on postprandial variations in the production and absorption of volatile fatty acids in the digestive tract of conscious pigs. Journal of Animal Science 64, 448-456.

Rérat AA, Giusi-Périer A \& Vaissade P (1993) Absorption balances and kinetics of nutrients and bacterial metabolites in conscious pigs after intake of maltose or maltitol-rich diets. Journal of Animal Science 71, 2473-2488.

Rérat AA, Vaugelade P \& Villiers PA (1980) A new method for measuring the absorption of nutrients in the pig: Critical examination. In Current Concepts of Digestion and Absorption in Pigs, pp. 177-214 [AG Low and IG Partridge, editors]. Ayr, UK: NIRD-HRI.

Roediger WEW (1995) The place of short-chain fatty acids in colonocyte metabolism in health and ulcerative colitis: the impaired colonocyte barrier. In Physiological and Clinical Aspects of Short Chain Fatty Acids, pp. 337-351 [JH Cummings, JL Rombeau and T Sakata, editors]. Cambridge: Cambridge University Press.

Sakamoto J, Nakaji S, Sugawara K, Iwane S \& Munakata A (1996) Comparison of resistant starch with cellulose diet on 1,2-dimethylhydrazine-induced colonic carcinogenesis in rats. Gastroenterology 110, 116-120.

Southgate DA (1998) How much and what classes of carbohydrate reach the colon. European Journal of Cancer Prevalence 7, S81-S82.

Stephen AM (1991) Starch and dietary fiber: their physiological and epidemiological interrelationships. Canadian Journal of Physiology and Pharmacology 69, 116-120.

Thorup I, Meyer O \& Kristiansen E (1995) Effect of potato starch, cornstarch, and sucrose on aberrant crypt foci in rats exposed to azoxymethane. Anticancer Research 15, 2101-2106.

Topping DL, Illman RJ, Taylor MN \& McIntosh GH (1985) Effects of wheat bran and porridge oats on hepatic portal venous volatile fatty acids in the pig. Annals of Nutrition and Metabolism 29, 325-331.

Van der Meulen J, Bakker GCM, Bakker JGM, de Visser H, Jongbloed AW \& Everts H (1997) Effect of resistant starch on net portal-drained viscera flux of glucose, volatile fatty acids, urea, and ammonia in growing pigs. Journal of Animal Science 75, 2697-2704.

Yen JT, Nienaber JA, Hill DA \& Pond WG (1991) Potential contribution of absorbed volatile fatty acids to whole-animal energy requirement in conscious swine. Journal of Animal Science 69, 2001-2012.

Young GP, McIntyre A, Albert V, Folino M, Muir JG \& Gibson PR (1996) Wheat bran suppresses potato starchpotentially colorectal tumorigenesis at the aberrant crypt stage in a rat model. Gastroenterology 110, 508-514. 